
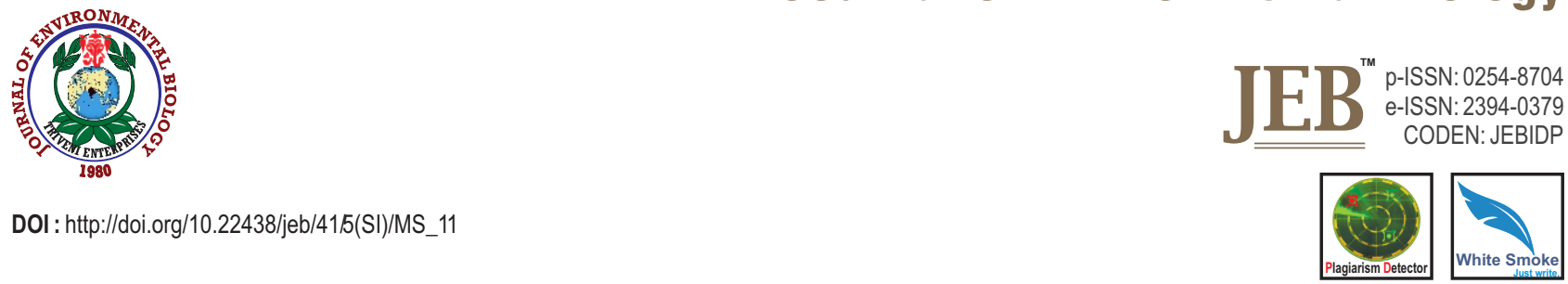

\title{
Inbreeding effect towards genetic markers and thermal tolerance in guppy Poecilia reticulate
}

\author{
F. Syukri ${ }^{1,2}$, H.H. Nadiatul ${ }^{3}$, T. Nakajima ${ }^{1}$ and M. Nakajima ${ }^{1 *}$ \\ ${ }^{1}$ Laboratory of Population Genetic Informatics, Graduate School of Agriculture, Tohoku University, Miyagi, 981-8555, Japan \\ ${ }^{2}$ International Institute of Aquaculture and Aquatic Sciences, Universiti Putra Malaysia, Serdang, 43400, Selangor Darul Ehsan, Malaysia \\ ${ }^{3}$ Department of Biology, Faculty of Science, Universiti Putra Malaysia, Serdang, 43400, Selangor Darul Ehsan, Malaysia \\ *Corresponding Author Email : masamichi.nakajima.b6@tohoku.ac.jp
}

\section{Abstract}

Aim: The guppy was used to demonstrate the effect of continues full-sib mating to the genetic changes and occurrence of inbreeding depression through heat stress tolerance.

Methodology: Inbreeding depression were assessed from data collected from microsatellite markers and thermal tolerance experiment. The AY and NA1 strains were selected for this experiment.

Results: With the progress in the inbred generations, significant decrease in thermal tolerance was observed. The observed ( $\mathrm{Ho})$ and expected ( $\mathrm{He})$ heterozygosity also decreased, indicating the on going inbred process. Significant correlation was observed only in the NA1 strain between thermal tolerances with multilocus heterozygosity (MLH) experiment both in Internal Relatedness (IR) and Standardize Heterozygosity (SH), respectively.

Interpretation: MLH can be used to determent inbreeding depression only when the samples are severely inbred.

Key words: Guppy, Inbreeding, Microsatellite, Thermal tolerance

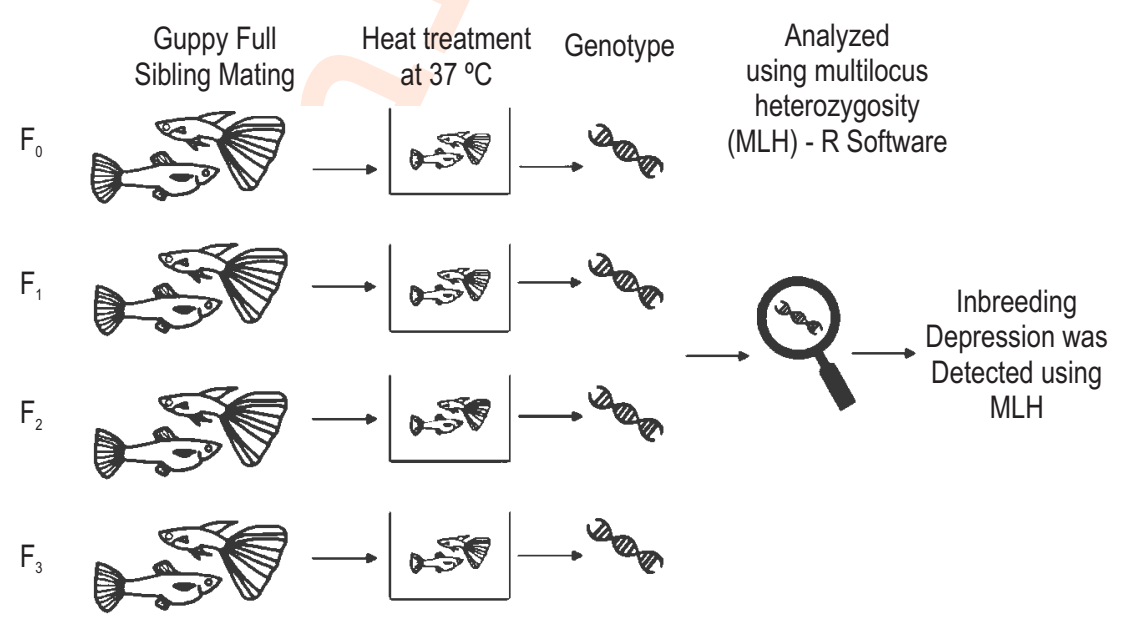

How to cite : Syukri, F., H.H. Nadiatul, T. Nakajima and M. Nakajima: Inbreeding effect towards genetic markers and thermal tolerance in guppy Poecilia reticulate. J. Environ. Biol., 41, 1194-1203 (2020). 


\section{Introduction}

Anthropogenic climate changes are occurring at an alarming rate leading to a global warming affect (New et al., 2011). These changes impact numerous ecosystems and destroy many species' natural habitats of several species. Heat stress due to global warming added more pressure to various species that might led to the population extinction (Martins et al., 2012; Sleadd et al., 2014). Although adaptation is an important key for survival; however, there are limits to what extent a specie can adapt to stress condition (Christiea et al., 2012; Narum et al., 2013). As most fishes are ectothermic, their physical and chemical activities are affected by the changes of water temperature. Increasing water temperature can also increase the metabolism of a fish until it reaches a certain threshold level, eventually losing its equilibrium leading to fatality. This event can even reduce the size of a natural population, endangering many species by increasing the chances of bottleneck and reduction in gene pool that would lead to inbreeding (Hare et al., 2011).

Naturally, fishes like guppy avoid sibling mating (Zajitschek et al., 2009; Johnson et al., 2010; Herdegen et al., 2014). However, due to existence of low number of individuals, the chances of inbreeding increases. During inbreeding process, mating between highly related pair reduces heterozygosity in the next generation due to similarity of high genetic material with paternal generation. Inbreeding depression occurs in species that have severely inbred for several generations, some of the indicator might consist of lower growth rate, poor physical fitness and decrease in fertility (Shikano et al., 2001; Zajitschek et al., 2009; Monson and Sadler, 2010; Zajitschek and Brooks, 2010). Heterozygosity has often been correlated with fitness relatively as assumption that individuals with high heterozygosity has been negatively correlated with inbreeding coefficient. Using microsatellite markers to assess heterozygosity are a common technique in population genetic for decades. The likelihood that fitness correlated loci may be randomly associated with noncoding region are reflected by the association between heterozygosity and fitness among population. Several researches documented on species such as European alpine marmots (Da Silva et al., 2006), Brent geese (Harrion et al., 2011) and guppy (Hardegen et al., 2014) have correlated between heterozygosity and fitness. However, it has been reported that heterozygosity and fitness may not be adequate to detect inbreeding depression as compared to pedigree method due to high variance at genomic level even in inbred population (Grueber et al., 2011). Due to these reasons, evaluation-using microsatellite markers is necessary to understand whether it is appropriate to detect inbreeding depression by implementing this method on a known inbred generation. In this experiment, we demonstrated possible correlation between heterozygosity and fitness measured by heat tolerance in inbred guppy strain reared under laboratory conditions.
Physical fitness plays an important role in surviving the ever-changing condition in the natural habitat. In laboratory condition, physical fitness is unchallenged and the effect of inbreeding depression may not be severe, as environment possesses little or no threat to the fish. Also, the probabilities for fish to be inbred are higher in close culture system due to lack of cross breed and small number of individuals in a population. Maintaining similar physical characteristic is the main reason for culturing commercial and laboratory fish in a close system. Bleakley et al. (2008) reported that commercially available fish have lower heterozygosity compared to wild-type, indicating close culture system may induce inbred fishes.

The main problem of inbreeding coefficient is the requirement of known generation that will not be available always in natural habitat. However, the alternative method is to examine the relationship between genotype markers. Microsatellite markers are common in assessing the fixation index (Fst) capable of estimating degree of inbreeding in a population by using five to fifteen markers (Chapuis and Estoup, 2007, Grueber et al., 2008; Forstmeier et al., 2012).

In the past decade, several studies have been reported to find correlation between multiple microsatellite markers to correlate with fitness. This method is commonly known as multi locus heterozygosity (MLH) correlation (Ala-honkola et al., 2009; Grueber et al., 2012; Herdegen et al., 2014). Assessing heterozygosity by MLH method has made it clear that the estimation was based on limited number of loci are predicted to associate weakly with inbreeding coefficient calculated from pedigree (Balloux et al., 2004). Since inbreeding coefficient and $\mathrm{MLH}$ do not measure the same quantity, the sensitivity of MLH can be increased by calculating the heterozygosityheterozygosity correlation (Alho et al., 2010). MLH correlation is assumption that calculation between two random sets of markers should be similar as MLH carry information on genome-wide heterozygosity.

Guppy (Poecilia reticulata) is a livebearer fish living in freshwater topical weather. It has been used as model organism reviewed by Nakajima and Taniguchi (2001), Oosterhout et al. (2007) and Reznick et al. (2008), similar to Medaka (Okamoto and Ishioka, 2010). Several guppy strains have been cultured in the laboratory using close culture system. These strains were used for experiments since variation such as body patterns, sizes and growth rate exist between strain. Previous study on physical fitness of guppy, challenges by salt water was documented indicating that the effect of fitness decrease as inbreeding generation increased (Shikano et al., 2001). The aim of this study was to evaluate the effect of inbreeding towards genetic changes and thermal tolerance in each generation produced. The multi locus heterozygosity and parental relatedness were used as evaluation tools to examine whether thermal tolerance were affected by the changes that occurred at genomic level. 


\section{Materials and Methods}

Samples and inbred guppy: Guppies were randomly selected from two strains that were cultured in a close system in the Laboratory of Population Genetic Informatics, Faculty of Science Agriculture, Tohoku University. The strains were AY and NA1 strain. The AY strain originated from Thailand, while the NA1 from Okinawa, Japan. The strains were kept in a close culture system since 2009 and 1999 for both AY and NA1 strains, respectively. The inbreeding experiment was initiated by parental selection comprising five pair of male and female from AY and NA1 strains. These pair we allowed to bred and reproduce in a two liters aquarium. The first-generation progeny $\left(F_{1}\right)$ from the parental generations $\left(P_{0}\right)$ were collected and separated into small families. A maximum number of five individuals were randomly selected from $F_{1}$ progeny to be catalog as a family. Each family were placed inside a one-litre container and periodically the water was changed. The progeny body length, total length, body width and height were measured every 30 days until it reached 180 days using Mitutotya ABS Solar Digimatic Caliper. New full sibling parental generation was created from $F_{1}$ generation by random pairing family sibling to produce second generations $\left(F_{2}\right)$ of inbred progeny. This cycle continues and several generations of inbred guppy were produced as illustrated in Fig. 1. Daily feed was given at libitum using medaka commercial diet and the survival rates were recorded.

Heat treatment tolerance: Matured guppies were randomly selected from each strain and generations to undergo heat tolerance experiment. Before the experiment started, guppies were acclimatized in a $30 \mathrm{I}$ insulated plastic container at $24^{\circ} \mathrm{C}$. Inside the container, six families of guppies were located for every experiment. After $24 \mathrm{hr}$ of acclimatization, temperatures was increased by $1^{\circ} \mathrm{C}$ for every $12 \mathrm{~min}$ until it reached $37^{\circ} \mathrm{C}$. The lethal temperature for guppy is $38.5^{\circ} \mathrm{C}$ (Chung, 2001), therefore, in this study $37{ }^{\circ} \mathrm{C}$ was selected for the thermal tolerance experiment to increase variation among inbred guppies. Survival times were recorded once the temperature reached $37^{\circ} \mathrm{C}$. Fin samples from the experimental fish were taken and stored in $99.8 \%$ ethanol for further analysis.

Molecular analysis: Total genomic DNA was extracted from all 364 fish individuals by Wizard ${ }^{\circledast}$ Genomic DNA Purification Kit (Promega) and stored at $4^{\circ} \mathrm{C}$ prior to PCR analysis. Screening was carried out by 19 microsatellite marker consisting of AC3, AGAT 11, ATCC2 (Olendorf et al., 2004), Pret 46, Pret 49, Pret 69, Pret 71, Pret 72, Pret 80 (Tanaguchi et al., 2003), G82, G 289, G 350 (Shen et al., 2007), Pr 21, Pr 40, Pr 80 (Becher et al., 2002), Pre 1, Pre 13 and Pre 15 (Paterson et al., 2005). PCR amplification was carried out with a Thermal Cycler (TaKaRa) in $10 \mu$ reaction mixtures containing 20-50ng of genomic DNA, 1.5 $\mathrm{mM} \mathrm{MgCl}, 1 \times$ PCR buffer, $0.1 \mu \mathrm{M}$ dNTPs, $0.2 \mu \mathrm{M}$ of each primer and $0.8 \mathrm{U}$ of Taq DNA polymerase (Promega). PCR was preset for 1 cycle consisting of denaturation for $1 \mathrm{~min}$ at $94^{\circ} \mathrm{C}$, followed by

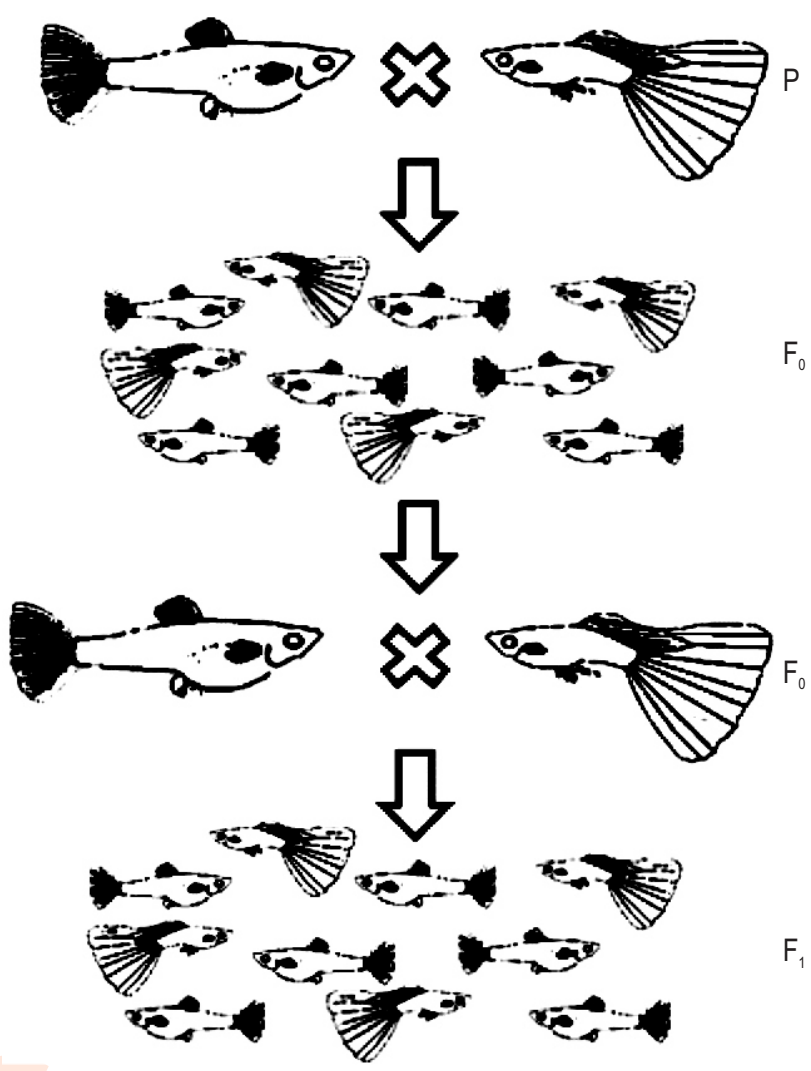

Fig. 1 : Producing full sibling mating guppy.

33 cycles consisting of denaturation for $30 \mathrm{sec}$ at $94{ }^{\circ} \mathrm{C}$, annealing for $30 \mathrm{sec}$ at $72^{\circ} \mathrm{C}$ for $30 \mathrm{sec}$. GeneScan ${ }^{\circledR} 400 \mathrm{HD}$ (ROX) size standard were mixed with the PCR product and electrophoresed using an $\mathrm{ABI} 3500 \mathrm{xl}$ Genetic Analyzer. All samples from the heat tolerance experiment were extracted for this experiment.

Genetic analysis: Individual genetic diversity (also known as internal relatedness (IR)) and standardized heterozygosity (SH) were calculated using Rhh as implemented in R statistical software from microsatellite markers data (Alho et al., 2010). The IR were measured by $I R=(2 H-\Sigma f i /(2 N-\Sigma f i)$; where $H$ is the loci number that are homozygous, $\mathrm{N}$ is the number of loci and fi is the frequency of the ith allele contained in the genotype. This is a measure of genetic diversity within each individual (an estimate of parental relatedness and we averaged over individuals for every generations in every strains). The SH measure heterozygosity loci at one individual divided by the average heterozygosity of the loci that were successfully genotyped for each individual (Coltman et al., 1998). Inbreeding coefficient (f) was calculated as per Wright (1922). Fixation index (Fst), observed $\left(H_{0}\right)$ and expected heterozygosity $\left(\mathrm{H}_{\mathrm{e}}\right)$ for each generation and strains were also calculated at all loci using GeneALex 6.5 (Peakall and Smouse, 2012). Correlation between individual heterozygosity with thermal tolerance were measured using Pearson Correlation by SPSS version 21 software. 


\section{Results and Discussion}

Inbreeding culture : The guppies were inbred until $3^{\text {rd }}$ generation $\left(F_{3}\right)$. Body length for each generation of inbred guppy were measured up to 180 days. Significant differences were noticed between male and female body length in each generation $(P<0.05)$. AY male from $F_{1}$ showed significant body growth in 180 days $(P<0.05)$ when compared with NA1 male $\left(F_{1}, F_{2}\right.$ and $\left.F_{3}\right)$ and AY male from the remaining generations. However, female guppy from both strains and generations showed in significant body growth. However, other factors such as mortality might have been affected by inbreeding since the rate of mortality increased as the inbred generation increased (Table 1).

Heat tolerance experiment : Guppies from AY and NA1 strains were exposed to $37^{\circ} \mathrm{C}$ water temperature and the survival time was recorded. The experiment was conducted to measure the fitness of inbred guppies. In NA1 strain, female illustrated significant tolerance to heat as compared to male guppy $(P<0.05)$. Significant heat tolerance was observed between AY and NA1 females $(P<0.05)$ (Fig. 2). The highest heat tolerance was observed in $A Y F_{1}$ at 339.4 minutes, while the lowest was noted at 90.1 min for NA1 male on the $F_{1}$. However, heat tolerance in all strains decreased at $F_{3}$ (Fig. 3). The $A Y$ strain showed higher resistance towards heat tolerance as compared to NA1 strains. A Kruskal-Wallis test illustrated significant decrease in heat tolerance in third generation in all strains except AY and NA1 female strains $(P<0.05)$. To evaluate the effect of size on heat tolerance experiment, correlation between body size and heat tolerance were analyzed. The NA1 strain for $F_{1}$ and $F_{2}$ showed no correlation between body size and heat tolerance whereas $F_{1}$ showed negative correlation, indicating that bigger body size showed less resistance to heat tolerance in both males and females, however it was insignificant $(P>0.05)$. Similar results were illustrated by $F_{1} A Y$ strains indicating heat stress were not affected by the body size of both male and female guppy.

Guppy samples ( $n=364)$ were genotyped using highly polymorphic microsatellite markers. After screening, only nine samples viz., Pret 46, Pret 49, Pret 69, Pret 71, Pret 72, Pret 80,

Table 1 : Inbred seed production separated by strains and generations. Parental generation $(P)$ started with five pairs of male and female. The first generation $\left(F_{1}\right)$ were cultured until it reached maturity and reproduced for several generations. In this experiment, up to fourth generation of full sibling inbred strain were produced. The number of survival individual decreased as the inbred generations increased. P: Parental generation, $F_{n}:$ Inbred $n$ generation, Family; no. of family, Invd; individual, AY; AY guppy strain, NA1; NA1 guppy strain, Surv\%; percentage on survival individual

\begin{tabular}{|c|c|c|c|c|c|c|c|}
\hline \multicolumn{4}{|c|}{ AY } & \multicolumn{4}{|c|}{ NA1 } \\
\hline Generation & Family & Invdl & Surv (\%) $\pm(S D)$ & Generation & Family & Invdl & Surv $(\%) \pm(S D)$ \\
\hline$P$ & 5 & 10 & & $P$ & 5 & 10 & \\
\hline $\mathrm{F}_{0}$ & 26 & 112 & $89(23)^{a}$ & $\mathrm{~F}_{0}$ & 59 & 238 & $92(15)^{a}$ \\
\hline $\mathrm{F}_{1}$ & 62 & 245 & $80(29)^{\mathrm{ab}}$ & $F_{1}$ & 56 & 230 & $79(23)^{b}$ \\
\hline $\mathrm{F}_{2}$ & 29 & 148 & $80(26)^{\mathrm{bc}}$ & $\mathrm{F}_{2}$ & 48 & 181 & $75(22)^{\mathrm{bc}}$ \\
\hline $\mathrm{F}_{3}$ & 35 & 112 & $75(30)^{\mathrm{bc}}$ & $\mathrm{F}_{3}$ & 58 & 243 & $74(29)^{\mathrm{bc}}$ \\
\hline
\end{tabular}
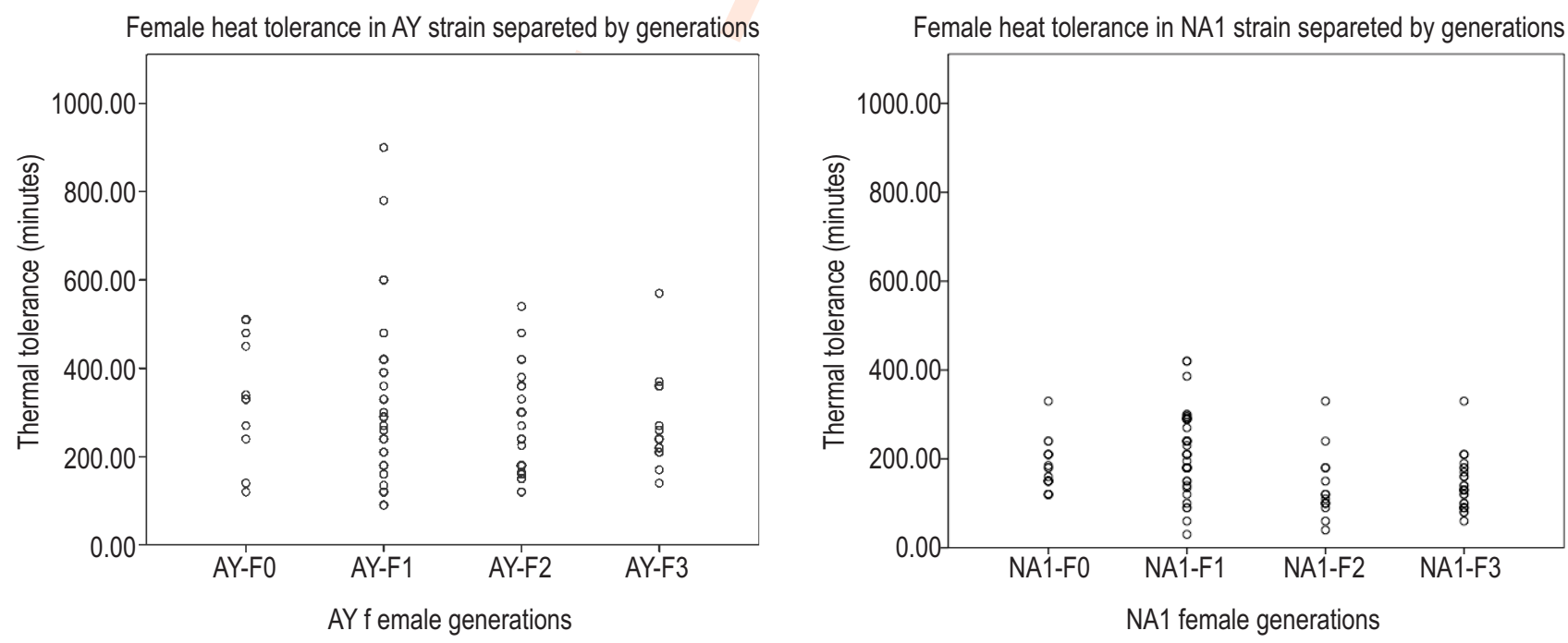

Fig. 2 : Dot plot of comparison between female thermal tolerance in AY and NA1 strains. Significant tolerances were observed between AY and NA1 compared by each generation. Decreases in thermal tolerances were observed as the inbreeding generation progress. Small alphabet $(x)=\operatorname{significant}$ by group. 

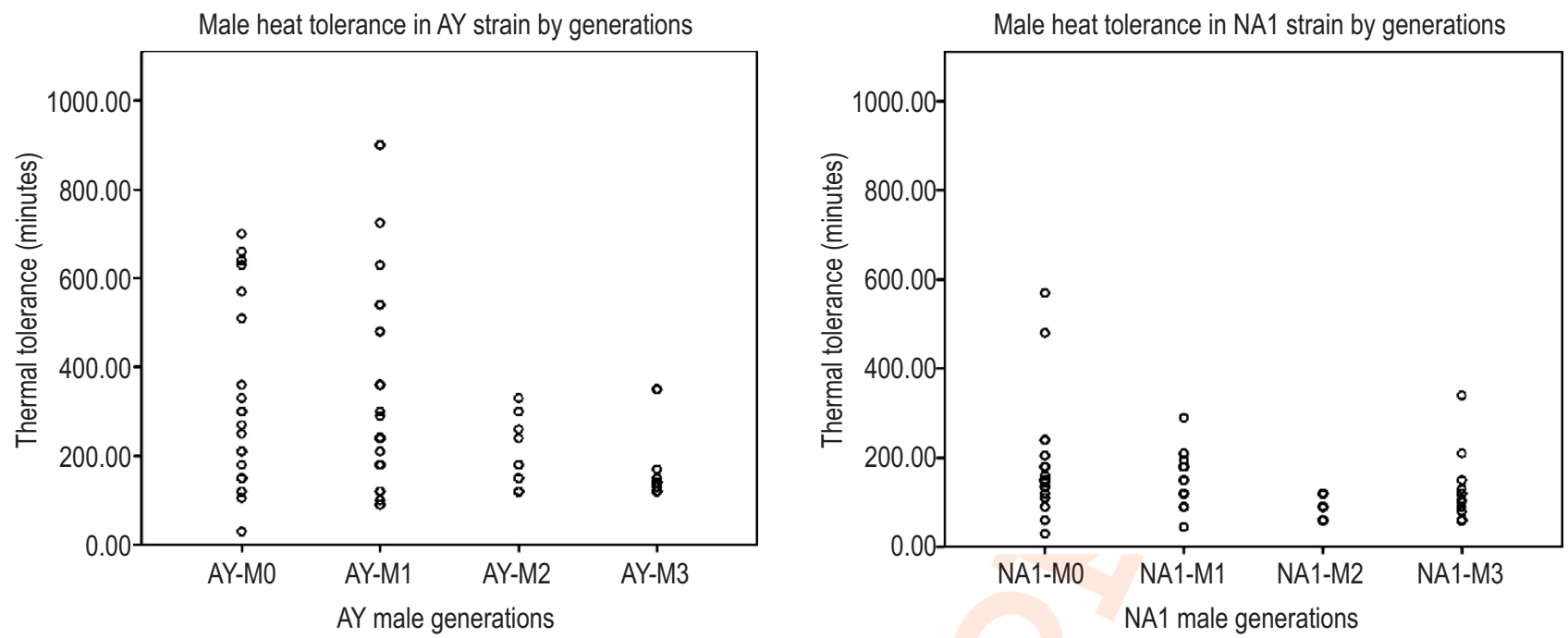

Fig. 3 : Dot plot of comparison between male thermal tolerance in AY and NA1 strains. AY strains have higher variations in thermal tolerance compared to NA1 male. Significant tolerances were observed between AY and NA1 compared by each generation. Small alphabet $(x)=$ significant by group.

AC3, AGAT 11 and ATCC2 was selected (Table 2). The remaining microsatellite markers were excluded due to low alleles number count and high existence of null alleles. All samples showed lower observed heterozygosity compared to expected heterozygosity (Table 3). Indicating that both strains were undergoing inbreeding program. In AY strain, observed heterozygosity was relatively higher as compared to NA1 strain. Both strains illustrated decrease in observed heterozygosity as the inbreeding generations increased. The AY strains observed heterozygosity started off with $\mathrm{Ho}=0.522$ and decreased in the third generation at $\mathrm{Ho}=0.282$. This probably indicates inbreeding occurred as mating between sibling progresse. Similar to AY, the NA1 showed significant drop of observed heterozygosity from $\mathrm{Ho}=0.479$ $(S E=0.055)$ at zero generation, while at third generation, the observed heterozygosity was $\mathrm{Ho}=0.186$ (SE=0.041). Lower fixation index (Fst) were observed in the experiment as the inbred generation increased. The AY strains had lower Fst as compared to NA1 strain. Increased Fst indicated that population have higher inbreeding level. The AY strain started off with $\mathrm{Fst}=0.102$ and in third generation it increased up to Fst $=0.230$. The NA1 strain had Fst $=0.245$ at zero generation of inbred guppy and increased drastically to Fst $=0.562$ in third inbred generation. Inbreeding increased Fst possibly due to decrease in allelic diversity as the inbreeding generation progressed.

Internal relatedness (IR) was calculated to measure parental distant at individual level. Individual with IR closer to one $(x>1)$ are assumed to be originated from parent with high genetic similarity whereas individual with IR zero $(x<0)$ we assumed to be originated from outbred parent. In this experiment, IR was used to determine whether it had effect on the fitness. There were no correlations observed in the AY strain between IR and thermal tolerance experiment at each level of the inbred guppy. In NA1 strains, significant correlation was not observed in first generation. However, in second and third generations significant negative correlation was observed for both male and female guppy $(p<0.05)$ (Fig. 4). These results illustrate that IR have significant effect on fitness. Individual with lower IR were able to survive longer in thermal tolerance test.

Similar to IR results, significant positive correlation between $\mathrm{SH}$ and thermal tolerance was observed in second and third NA1 guppy inbred generations for both male and female (Fig. 5). This indicates that individuals with high standardized heterozygosity were capable to sustain longer in thermal tolerance experiment.

Inbreeding severely affected the survival rate of guppies. As the inbred generation increased, the rate of mortality also increased. There are several explanations to the increased mortality rate. One possible reason is due to increase in deleterious alleles caused by high number of homozygous alleles produced during full sibling mating and at the same time reduced fitness due to inbreeding depression. The mortality will help to reduce inbreeding depression in the strain as recessive deleterious alleles might have purged from the population (Hendrick, 1994). The number of individuals produced would differ from generation to generation, however, the increased consistency of mortality is observed as inbreeding generation progresses. This suggests that purging may take place during the inbreeding process.

Different trend was observed between $A Y$ and NA1 strains, which probably caused distinctive outcome between original variability and tolerance. The AY strain originated in Thailand, while NA1 in Okinawa, Japan. Both strains have been cultured in laboratory for several years suggesting that thermal 

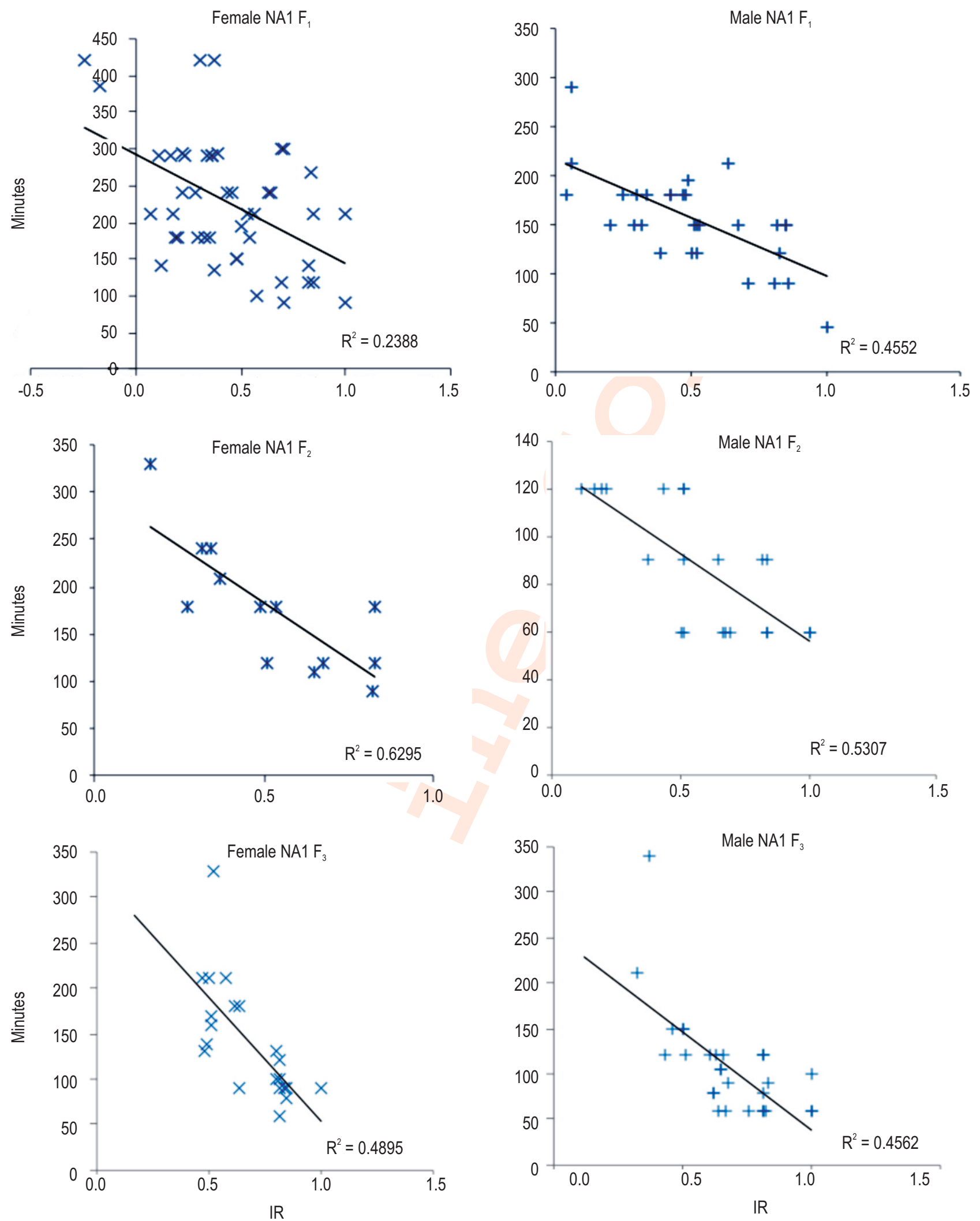

Fig. 4 : Correlations between internal relatedness (IR) with thermal tolerance in second and third generation of inbred NA1 strain. Negative correlation between IR and thermal tolerance were observed. Second and third generation of female and male NA1 was significantly correlated $(p<0.05)$. 

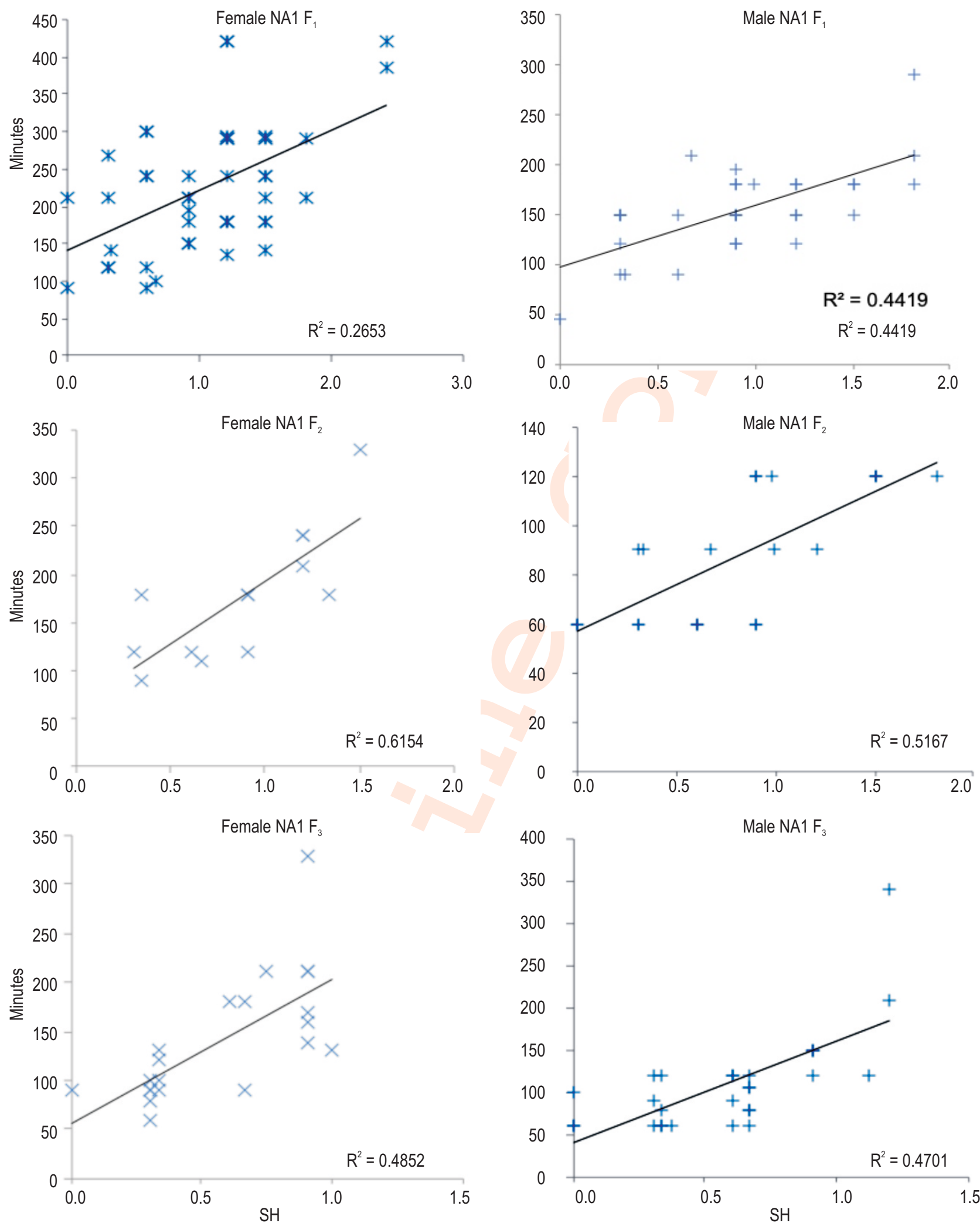

Fig. 5 : Correlations between standardized heterozygosity (SH) with thermal tolerance in NA1 male and female in second and third inbred generation. Significant positive correlation between SH and thermal tolerance were observed $(p<0.05)$. Individual with high SH survives longer in thermal tolerance experiment. 
Table 2 : Selected microsatellite markers used in this experiment

\begin{tabular}{|c|c|c|c|c|c|c|}
\hline Locus & Repeat Motif & Primer Sequences & $\begin{array}{l}\text { GenBank } \\
\text { Accession no. }\end{array}$ & $\begin{array}{l}\text { No. of } \\
\text { alleles }\end{array}$ & $\begin{array}{l}\text { Allele range } \\
\text { (bp) }\end{array}$ & Authors \\
\hline ATCC2 & $(\text { AATG })_{20}$ & $\begin{array}{l}\text { F:AGTCACGACGTTGTATTCAGACATACTGT } \\
\text { AGCCCTGCR:CATTCACAATTAGGTAGGCAGC }\end{array}$ & BV097133 & 15 & $234-319$ & Olendorf et al., (2004) \\
\hline AC3 & $(\mathrm{CA})_{12}$ & $\begin{array}{l}\text { F:AGTCACGACGTTGTACAGAATCCTTTCTGC } \\
\text { TTTCTGGR:TTGTCCTCATAGGTGCACTC }\end{array}$ & BV097135 & 22 & $236-288$ & \\
\hline AGAT11 & $(\mathrm{AGAT})_{31}$ & $\begin{array}{l}\text { F:AGTCACGACGTTGTAGAGTCCATATCAG } \\
\text { AAGGTGCR:GGTGTTCTGACGATGTATGC }\end{array}$ & BV097141 & 27 & 213-381 & \\
\hline Pret-46 & $(\mathrm{CA})_{27}$ & $\begin{array}{l}\text { F:AGTCACGACGTTGTAAACCCTAATGACT } \\
\text { CCCAACAR:CGACCCACCAGTAATCCAA }\end{array}$ & AB100334 & 7 & 170 & Watanabe et al., (2003) \\
\hline Pret-49 & $(\mathrm{CA})_{18}$ & $\begin{array}{l}\text { F:AGTCACGACGTTGTAGGAAATGGCAG } \\
\text { AGGAAGR:TGTGGGCATTAAAAAGTGT }\end{array}$ & AB100336 & 7 & 251 & \\
\hline Pret-69 & $(G T)_{10}$ & $\begin{array}{l}\text { F:AGTCACGACGTTGTAGGTTGCTGCAT } \\
\text { GTGGTCR: CTAGCGTTCCTGCATTCTG }\end{array}$ & AB100347 & 6 & 116 & \\
\hline Pret-80 & $(\mathrm{GT})_{14}+(\mathrm{GA})_{11}$ & $\begin{array}{l}\text { F:AGTCACGACGTTGTAGGAAGGGAGGGGA } \\
\text { GGATR: CACTTCAGCAGGGCAGACTA }\end{array}$ & AB100354 & 7 & 214 & \\
\hline Pret-71 & $(G A)_{10}+(G A)_{9}$ & $\begin{array}{l}\text { F:AGTCACGACGTTGTATGGATCGGTGCTG } \\
\text { AAGTTATR:TTTGCCCGTCTCTTTGG }\end{array}$ & AB100348 & 4 & 250 & \\
\hline Pret-72 & $(G A) 26$ & $\begin{array}{l}\text { F:AGTCACGACGTTGTAGCGCAAGTAGGAC } \\
\text { GTAGAAR:ACCGAACTGTGGACGACT }\end{array}$ & AB100349 & 6 & 148 & \\
\hline
\end{tabular}

Table 3: Genetic changes in inbred AY and NA1 strain guppy

\begin{tabular}{|c|c|c|c|c|c|}
\hline Strains & $\mathrm{N}$ & Ho(SE) & $\mathrm{He}$ (SE) & Fst & $f$ \\
\hline AY-FO & 30 & $0.522(0.062)$ & $0.626(0.064)$ & 0.102 & 0.250 \\
\hline AY-F1 & 60 & $0.452(0.127)$ & $0.582(0.057)$ & 0.158 & 0.375 \\
\hline AY-F2 & 45 & $0.382(0.057)$ & $0.508(0.057)$ & 0.233 & 0.500 \\
\hline AY-F3 & 26 & $0.282(0.088)$ & $0.39(0.074)$ & 0.230 & 0.590 \\
\hline NA1-F0 & 45 & $0.479(0.055)$ & $0.643(0.062)$ & 0.245 & 0.250 \\
\hline NA1-F1 & 75 & $0.371(0.055)$ & $0.601(0.072)$ & 0.375 & 0.375 \\
\hline NA1-F2 & 34 & $0.285(0.075)$ & $0.531(0.065)$ & 0.453 & 0.500 \\
\hline NA1-F3 & 49 & $0.195(0.043)$ & $0.528(0.089)$ & 0.562 & 0.590 \\
\hline
\end{tabular}

tolerance gene from generation to generation. Physical adaptation can occur even in local scale through stress-induced environment such as global warming and climate differences (Eliason et al., 2011, Atkins and Travis, 2010; Newton et al., 2010). AY strain origin population may have been exposed to temperature range of $25^{\circ} \mathrm{C}$ to $36^{\circ} \mathrm{C}$, while NA1 strain originated from Okinawa population were exposed to temperature ranging from $18^{\circ} \mathrm{C}$ to $30^{\circ} \mathrm{C}$ (Meteorology, 2013). The Guppy original population assessed to different thermal environments and impose a selective pressure upon local stocks clearly resulted in the development of population specific thermal tolerance to their localized thermal conditions. In NA1 strain, it was recorded to be closed culture for more than 30 generations. It has a high rate of reproduction, but low survivability towards thermal tolerance. This indicates that NA1 strain were able to strive in control environment, but have lower tolerance in stress condition. The AY strain has been cultured in close culture system since 2009. As compared to NA1 it has been less in bred and has showed high variation in thermal tolerance experiment. This indicates that inbred fish can strive in control environment, whereas it has less tolerance to stress since the NA1 indicated low variation in thermal tolerance experiment. When external stress such as increase in water temperature or change in water chemical composition, inbred strain will shown low fitness as compared to less inbred counterpart. This event was commonly observed in hatchery fish such as salmon, indicating that hatchery strains have weaker fitness in comparison to wild population (KallioNyberg et al., 2011; Beamish et al., 2012).

The changes in genomic level were observed as inbreeding increased. Fixation index increased for both AY and NA1 strains, indicating loss of heterozygosity from generation to generation. Fixation index was high in NA1 strain because NA1 strain were kept for longer duration in close culture system as compared to AY strain. Other reasons for increase inbreeding level is due to that female guppy does not seem to discriminate closely related male and fertilized eggs might be originated from several males (Pitcher et al., 2008). This would increase the chances of inbreeding in a population with low individual numbers. Although Herdegen et al. (2014) demonstrated that 
female guppy prefer male with higher orange body coloration, in this experiment the male were randomly selected from sibling level reducing the chance of females to select outbred males. The decrease in heterozygosity for both strains might also be due to parental generation which were already inbred (Gkafas et al., 2019, Riquet et al., 2019).

The IR and SH were used to compare the effect of inbreeding towards genetic changes with fitness correlated traits. In AY strain, significant correlation was not observed between IR and $\mathrm{SH}$ in thermal tolerance experiment. However, in NA1 strain correlation was observed first generation until third generation of inbred male and female on comparing it with thermal tolerance of both IR and SH calculation. This indicated that MLH may not be sensitive enough to be used in a wild population, where inbreeding rarely occurrs. Previous studies have stated that the correlation between inbreeding coefficient with standardized heterozygosity and internal relatedness are weak in wild population (Luquer et al., 2011; Grueber et al., 2008; Grueber et al., 2011; Herdegen et al., 2014), whereas, correlation between MLH and fitness may occurr when population are severely inbred. The MLH method will be useful to evaluate inbreeding depression in wild population. Correlation between MLH and fitness revealed that the possible inbreeding process might have severely occurred in the population, hence, precautions should be reduce the effect of inbreeding depression, most importantly to avoid extinction.

In summary, this study demonstrates the outcome of full sibling mating to thermal tolerance resistance in guppys. The correlation between MLH and fitness was also observed in highly inbred organism. This method can be useful to assess wild population as exhibited by the inbred guppy, thereby indicating that $\mathrm{MLH}$ are relevant to evaluate inbreeding depression in a population.

\section{References}

Ala-honkola, O., A. Uddstrom, B.D. Pauli and K. Lindstrom: Strong inbreeding depression in male mating behaviour in a poeciliid fish. J. Evolut. Biol., 22, 1396-1406 (2009).

Alho, J.S., K. Valimaki and J. Merila: Rhh: An R extension for estimating multilocus heterozygosity and heterozygosity-heterozygosity correlation. Molec. Ecol. Res., 10, 720-722 (2010).

Becher, S.A., S.T. Russell and A.E. Magurran: Isolation and characterization of polymorphic microsatellites in the Trinidadian guppy (Poecilia reticulata). Molec. Ecol. Not., 2, 456-458 (2002).

Bleakley, B.H., A.C. Eklund and E.D. Brodie: Are designer guppies Inbred? Microsatellite Variation in five strains of ornamental guppies, Poecilia reticulata, used for behavioral research. Zebrafish, 5, 1 (2008).

Chapuis, M.P. and A. Estoup: Microsatellite null alleles and estimation of population differentiation. Mol. Biol. Evol., 24, 621-631 (2007).

Christiea, M.R., M.L. Marinea, R.A. French and M.S. Blouina: Genetic adaptation to captivity can occur in a single generation. PNAS, 109, 238-242 (2012).
Da Silva, A., G. Luikart, N.G. Yoccoz, A. Cohas and D. Allaine: Genetic diversity-fitness correlation revealed by microsatellite analyses in European alpine marmots (Marmota marmota). Conser. Gen., 7, 371-382 (2006).

Gkafas, G.A., M. Hatziioannou, E.E. Malandrakis, C.S. Tsigenopoulos, I.T. Karapanagiotidis, E. Mente, D. Vafidis and A. Exadactylos: Heterozygosity fitness correlations and generation interval of the Norway lobster in the Aegean Sea, eastern Mediterranean. J. Biol. Res-Thessaloniki, 26, 14 (2019). https://doi.org/10.1186/s40709019-0103-0

Grueber, C.E., J.M. Waters and I.G. Jamieson: The imprecision of heterozygosity-fitness correlations hinders the detection of inbreeding and inbreeding depression in a threatened species. Molec. Ecol., 20, 67-79 (2011).

Hare, M.P., L. Nunney, M.K. Schwatz, E.D. Ruzzante, M. Burford, R.S. Waples, K. Ruegg and F.F. Palstra: Understanding and estimating effective population size for practical application in marine species management. Conser. Biol., 25, 438-449 (2011).

Harrison, X.A., S. Bearhop, R. Inger, K. Colhoun, G.A. Gudmundsson, D. Hodgson, G. Mcelwaine and T. Tregenza: Heterozygosity-fitness correlations in a migratory bird: An analysis of inbreeding and single-locus effects. Molec. Ecol., 20, 4786-4795 (2011).

Hedrick, P.W.: Purging inbreeding depression and the probability of extinction: Full-sib mating. Heredity, 75, 363-372 (1994).

Herdegen, M., K. Dudka and J. Radwan: Heterozygosity and orange coloration are associated in the guppy (Poecilia reticulata). J. Evol. Biol., 27, 220-225 (2014).

Johnson, A.M., G. Chappell, A.C. Price, F.H. Rodd, R. Olendorf and K.A. Hughes: Inbreeding depression and Inbreeding avoidance in a natural population of guppies (Poecilia reticulata). Ethology, 116, 448-457 (2010).

Martins, G.E., G.H. Hinch, D.A. Patterson, M.J. Hague, S.J. Cooke, K.M. Miller, D. Robichaud, K.K. English, P. Anthony and A.P. Farrell: High river temperature reduces survival of sockeye salmon (Oncorhynchus nerka) approaching spawning grounds and exacerbates female mortality. Can. J. Fish. Aquat. Sci., 69, 330-342 (2012).

Monson, C.A. and K.C. Sadler: Inbreeding depression and outbreeding depression are evident in wild-type zebrafish lines. Zebrafish, 7, 189-197 (2010).

Nakajima, M. and N. Taniguchi: Genetics of the guppy as a model for experiment in aquaculture. Genetica, 111, 279-289 (2001).

Narum, S.R., N.R. Cambell, K.A. Meyer, M.R. Miller and R.W. Hardy: Thermal adaptation and acclimation of ectotherms from differing aquatic climates. Molec. Ecol., 22, 3090-3097 (2013).

New, M., D. Liverman, H. Schroder and K. Anderson: Four degrees and beyond: the potential for a global temperature increase of four degrees and its implications. Phil. Trans. R. Soc., 369, 6-19 (2011).

Olendorf, R., B. Reudi and K.A. Hughes: Primers for 12 polymorphic microsatellite DNA loci from the guppy (Poecilia reticulata). Molec. Ecol. Notes, 4, 668-671 (2004).

Oosterhout, C.V., A.M. Smith, B. Hanfling, I.W. Ramnarine, R.S. Mohammed and J. Cable: The guppy as a conservation model: Implications of parasitism and inbreeding for reintroduction success. Conser. Biol., 21, No. 6 (2007).

Paterson, I.G., E. Crispo, M.T. Kinnison, A.P. Hendry and P. Bentzen: Characterization of tetranucleotide microsatellite markers in guppy (Poecilia reticulata). Molec. Ecol. Notes, 5, 269-271 (2005).

Peakall, S. and P.E. Smouse: GenAlEx 6.5: Genetic Analysis in Excel. 
Population genetic software for teaching and research - an update. Bioinfor., 28, 2537-2539 (2012).

Riquet, F., C. Lieutard-Haag, G., Serluca, L. Woodall, J. Claude, P. Louisy and N. Bierne : Effective population size and heterozygosity-fitness correlations in a population of the Mediterranean lagoon ecotype of long-snouted seahorse Hippocampus guttulatus. Conserv. Genet., 20, 1281-1288 (2019).

Reznick, D.N., C.K. Ghalambor and K. Crooks: Experimental studies of evolution in guppies: A model for understanding the evolutionary consequences of predator removal in natural communities. Molec. Ecol., 17, 97-107 (2008).

Shen, X., G. Yang and M. Liao: Development of 51 genomic microsatellite DNA markers of guppy (Poecilia reticulata) and their application in closely related species. Molec. Ecol. Notes, 7, 302306 (2007).

Shikano, T., T. Chiyokubo and N. Taniguchi: Effect of inbreeding on salinity tolerance in the guppy (Poecilia reticulata). Aquacult., 202, 45-55 (2001).

Sleadd, I.M., M. Lee, D.O. Hassumani, T.M.A. Stecyk, O.K. Zeitz and B.A. Buckley: Sub-lethal heat stress causes apoptosis in an
Antarctic fish that lacks an inducible heat shock response. J. Ther. Biol., 44, 119-125 (2014).

Watanabe, T., M. Yoshida, M. Nakajima and N. Taniguchi: Isolation and characterization of 43 microsatellite DNA markers for guppy (Poecilia reticulata). Molec. Ecol. Notes, 3, 487-490 (2003).

Watanabe, T., M. Yoshida, M. Nakajima and N. Taniguchi: Isolation and characterization of 43 microsatellite DNA markers for guppy (Poecilia reticulata). Molec. Ecol. Notes, 3, 487-490 (2003).

Zajitschek, S.R.K., A.L. Lindholm, J.P. Evans and R.C. Brooks: Experimental evidence that high levels of inbreeding depress sperm competitiveness. J. Evol. Biol., 22, 1338-1345 (2009)

Zajitscheka, S.R.K., C. Robert and R.C. Brooks: Inbreeding depression in male traits and preference for outbred males in Poecilia reticulata. Behavi. Ecol., 21, 884-891 (2010).

Okamoto, $\mathrm{H}$. and A. Ishioka: Zebrafish Research in Japan and the National BioResource Project. Exp. Anim., 59, 9-12 (2010).

Kallio-Nyberg, I., I. Saloniemi, E. Jutila and E. Jokikokko: Effect of hatchery rearing and environmental factors on the survival, growth and migration of Atlantic salmon in the Baltic Sea. Fisher. Res., 109, 285-294 (2011). 